\title{
Research on Optimal Product Attributes Selection of New Energy Vehicles
}

\author{
CHONG LUO ${ }^{1, a}$, CHUNJIE CHI ${ }^{2, b}$ \\ ${ }^{1,2}$ School of business, East China University of Science and Technology, Shanghai, China \\ alc95813344@163.com, bjchi@ecust.edu.cn
}

\begin{abstract}
Keywords: New Energy Vehicles; Conjoint Analysis; Attribute Preference.
Abstract. New energy vehicle, as the national strategic emerging industry, has received strong support from the government in recent years, but the industrialization development of new energy vehicle is not ideal. On the one hand, most of the research on new energy vehicle attributes is qualitative, which hindered the promotion of new energy vehicles in the market to some extent. On the other hand, the ability and the willingness of manufacturers should be taken into consideration. This paper uses the conjoint analysis to construct a new energy vehicle attributes and level model. The new energy vehicles manufacturers are introduced into the model as well. A series of properties of preference are found to explore the optimal choices of new energy vehicles.
\end{abstract}

\section{Introduction}

With the worsening of ecological environment as well as the use of energy increasingly nervous, the development of new energy vehicles has become an inevitable trend and received strong support from the state recent years. However the industrialization development of new energy vehicles is not ideal. We should realize that new energy vehicles have great difference between traditional internal combustion engine vehicles, especially the consumers' preferences for product attributes. At present most of the research of the importance of new energy vehicles attributes are qualitative. Guohu Xu (2010) has studied the influence factors of purchase decision by questionnaire in the focus group meeting through 20 new energy vehicle sales staffs. He concluded five new energy vehicle purchase decision factors: after-sales service impact factor, cost factors, vehicle quality influence factor, the use of energy consumption factor and the surrounding factors. Nan Ye (2012) found the restricting factors of new energy vehicles have: limited range, the respect such as infrastructure availability constraints. Minjie Zhou (2013) had made a regression analysis of the Shanghai international auto city try-out driving center data provided by the electric car drivers. She finally concluded that the electric car buying decision significant influencing factors, including age characteristics, use preferences, driving range, and government policy.

These scholars study the affecting factors in the qualitative research, but few of them does a further research from the perspective of quantitative especially taking the impact factor positioning to a specific level. This paper uses the conjoint analysis to construct the construction of new energy vehicles attribute and level model. But conjoint analysis, while significantly contributing to the product design process, has the limitation of designing a product based only on input from the consumer. Rather than adhering only to consumer preferences, there are instances when a better design will result from using both consumer and producer input. The ability and the willingness of manufacturers should be included in the scope which no one has tried. Conjoint analysis is used to collect data from the two parties, which is then used to determine an optimal or near-optimal design based on total multiparty loss.

\section{Methods and Models}

A model is needed that designs a series of productions that minimizes the total multiparty loss. Multiparty in this case refers to both customers and producer (new energy vehicles manufacturers). Loss is the distance each party is from their preferred choice, and is loosely based on the concept of the Taguchi loss function. 
This model contains customer part worth's matrices $\mathrm{D}(\mathrm{m})$ for each customer attributes $\mathrm{I}=1,2 \cdots . \mathrm{i}$. Each customer attribute has $\mathrm{J}=1,2 \cdots \mathrm{j}$ levels. There are $\mathrm{M}=1,2 \cdots \mathrm{m}$ customers. Entries in matrix, $\mathrm{d}_{\mathrm{ijm}}$, are the utility of customer $\mathrm{m}$ for level $\mathrm{j}$ of attribute $\mathrm{i}$. For every possible product design, it also has a matrices C(ij) . For a specific product, it can only have one level for every one attribute. So, C(ij) was completely made up of 0 and 1.1 means that the product contains the specific level for the attribute. So, a total utility for each customer $\mathrm{M}$ can be derived by summing over each attribute at the specified level and adding this to the constant value:

$$
V_{\mathrm{m}}=\Sigma_{\mathrm{j}=1}^{J} \Sigma_{\mathrm{i}=1}^{\mathrm{J}} \mathrm{d}_{\mathrm{ilm}} * \mathrm{c}_{\mathrm{ij}}
$$

This model contains producer part worths matrices $\mathrm{D}(\mathrm{n})$ for each producer attributes $\mathrm{I}^{\prime}=1,2 \ldots \mathrm{I}$ ' Each producer attribute has $J^{\prime}=1,2 \ldots j$ ' levels. There are $\mathrm{N}=1,2 \ldots \mathrm{n}$ customers. Entries in matrix, $\mathrm{A}_{y^{\prime} \gamma_{u}}$, are the utility of producer $n$ for level $\mathrm{j}$ ' of attribute i'. So, a total utility for each customer $\mathrm{N}$ can be derived by summing over each attribute at the specified level and adding this to the constant value:

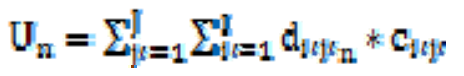

Average utilities are then defined for each design:

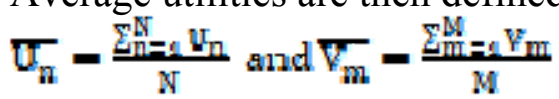

By conjoint analysis, for all production there is a maximum $\mathrm{V}^{*}$ and $\mathrm{U} *$. The objective is to minimize the sum of $Z$ the sum of the distances of the utility values of the chosen product design from the maximum possible utility values for both customers and producers, where:

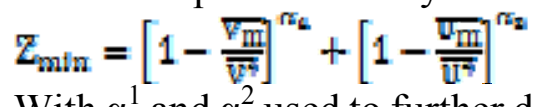

With $\alpha^{1}$ and $\alpha^{2}$ used to further define the loss functions. $\alpha^{1}$ and $\alpha^{2}$ are normally set equal to 2 . With this function, the total "loss" value makes comparisons between results more realistic and understandable.

\section{A real application}

This model will now be applied to a real problem. This study was done with the help of a manufacturer which produces the new energy vehicles. The data of producer mainly comes from the questionnaires of 9 staffs from sales department and design department in the new energy vehicle manufacturer enterprise. The data of consumers mainly comes from 217 Shanghai residents who plan to have a car. Conjoint analysis is used to collect data from the two parties, which is then used to determine an optimal or near-optimal design based on total multiparty loss.

Referencing some scholar's research of new energy vehicles and adding some new elements, this article mainly use 4 attributes and 3 levels in the conjoint analysis.(1) Driving Mileage: Driving mileage is one of the most important factors that restrict new energy vehicle marketing. "Range anxiety" is a typical problem which causes the people doesn't want to buy new energy vehicles. When they want to buy a new energy vehicle, they will first consider the relationship between the range and commuting distance. As a result, they are very concerned about the mileage range of the car. 80KM: <The National Electric Passenger Car Technical Conditions $>$ in China require that driving mileage should be not less than $80 \mathrm{~km}$. 150km and 250km: Subsidy policy in 2013 specified that 150 $\mathrm{km}$ is the boundary between subsidized prices.(2) Price Level: Price level is often one of the important factors to customers. Selection of price attribute level mainly refers to the current price of pure electric car market. Now the market is the mainstream of pure electric vehicles including three categories. Less than 100,000 yuan: Some domestic low-speed electric cars occupy a certain market share because of its low price; 100,000-200,000 yuan: Some common sino-foreign joint ventures and domestic brand; More than 200,000 yuan: some high - end brands. (3)Charging Way: Charging way of new energy vehicles always including: Home charge: it will take 6 to 8 tation hours. The typical fault is the charging time too long. However the customer can take every night to charge the car; Quick charge: it may just take 15 minutes which is as convenient as refueling in the gas station. However, the numbers of stations become the main restricted factors;Battery swap: it also can be 
quickly added energy but the cost is higher. (4) Maximum Speed: Maximum speed also affects the consumers' purchase decision. 80km/h: <The National Electric Passenger Car Technical Conditions $>$ in China require that maximum speed should be not less than $80 \mathrm{~km} / \mathrm{h} .120 \mathrm{~km} / \mathrm{h}$ : The typical level of mid-range pure electric vehicles, such as Roewe E50, nissan leaf. So, this paper finally choose driving mileage, price level, maximum speed and charging ways as the attributes of conjoint analysis and every attribution has three levels. As shown in the figure 1:

\begin{tabular}{|c|c|c|c|c|c|}
\hline \multicolumn{6}{|c|}{ Conjoint Analys is Attributes and Levels } \\
\hline Attributes 1 : & Charging & g Way: $\mathrm{I}$ & Home charge & Quick charge & Battery swap \\
\hline Attributes 2: & Driving & Mileage: & $=80-150 \mathrm{~km}$ & $150-250 \mathrm{~km}$ & $>250 \mathrm{~km}$ \\
\hline Attributes 3 : & Maximum & Speed : & $<80 \mathrm{kmph}$ & $80-120 \mathrm{kmph}$ & $>120 \mathrm{kmph}$ \\
\hline Attributes 4: & Price Le & eve1: & $<1 \mathrm{OOK}$ & $100-200 K$ & $>200 K$ \\
\hline
\end{tabular}

Figure. 1. Conjoint Analysis Attributes and Levels

The questionnaire was designed by SPSS-PC software pack-age with the Categories option. A set of 9 cards was generated, each card containing one level from each of the attributes and representing a possible product design. The set of cards forms a fractional factorial design (which is also orthogonal) generated using SPSS-PC. As shown in the figure 2:

\begin{tabular}{|c|c|c|c|c|c|}
\hline & Number & Charging Way & Driving Mileage & Maximum Speed & Price Level \\
\hline 1 & 1 & Battery swap & $>250 \mathrm{~km}$ & $<120 \mathrm{kmh}$ & $<100 \mathrm{k}$ \\
2 & 2 & Battery swap & $80-150 \mathrm{~km}$ & $80-120 \mathrm{kmh}$ & $>200 \mathrm{k}$ \\
3 & 3 & Quick charge & $>250 \mathrm{~km}$ & $<80 \mathrm{kmh}$ & $>200 \mathrm{k}$ \\
4 & 4 & Home charge & $80-150 \mathrm{~km}$ & $<80 \mathrm{kmh}$ & $<100 \mathrm{k}$ \\
5 & 5 & Home charge & $>250 \mathrm{~km}$ & $80-120 \mathrm{kmh}$ & $100-200 \mathrm{k}$ \\
6 & 6 & Home charge & $150-250 \mathrm{~km}$ & $<120 \mathrm{kmh}$ & $>200 \mathrm{k}$ \\
7 & 7 & Quick charge & $80-150 \mathrm{~km}$ & $<120 \mathrm{kmh}$ & $100-200 \mathrm{k}$ \\
8 & 8 & Battery swap & $150-250 \mathrm{~km}$ & $<80 \mathrm{kmh}$ & $100-200 \mathrm{k}$ \\
9 & 9 & Quick charge & $150-250 \mathrm{~km}$ & $80-120 \mathrm{kmh}$ & $<100 \mathrm{k}$ \\
\hline
\end{tabular}

Figure. 2. Questionnaire Design and Card Design

Each card represents a production that customer/producer may receive. 9 staffs from sales department and design department in the new energy vehicle manufacturer enterprise and 217 Shanghai residents who plan to have a car were invited to conduct this survey. Every one of them was got 9 cards in the survey. The cards were sorted by the subjects from most preferred to least preferred. A part worths value was then derived for each level of each of the customer attributes from the final ordering of the cards. The whole process carried out in accordance with the conjoint analysis procedures.

\section{Results}

SPSS-PC software package with the Categories option was used to analyze the results of the two conjoint data collections. In fact, we get two parts data, one from the customer and the other from the producer. According to the traditional use conjoint analysis, the two data sets could be used to design an optimal production respectively, one that is the optimal for the customer $\mathrm{V}^{*}$ and one that is the optimal for the producer $U^{*}$. However, they will choose the most advantageous to themselves. For example, customer will choose the production which can run farther and cheaper but it is not possible for producer because of the limitation of cost. So, the $\mathrm{V}^{*}$ is always not the preferred by the producer and $\mathrm{U}^{*}$ is always not the preferred by the customer. 
However, we can establish relationship between the two data sets from the model we designed in 2.2. The model can be used to get a balanced production that is "better". As a result, the optimal production by only one set of data can be obtained which is will be the optimal from both the customer and producer. A series of more balanced production can then be designed satisfy customer and producer.

(1) Customer Optimal: Based on questionnaire data we collected, an average of the requirements of most people, customers prefer a production with the following attributes and levels in a total utility value $\mathrm{V}^{*}=5.33$ : According to the SPSS analyze, we can get the "attribute importance degree" of customers as Table 1:

Table. 1. Attribute Importance Degree

\begin{tabular}{|l|c|}
\hline Charging Way & 24.138 \\
Driving Mileage & 10.345 \\
Maximum Speed & 6.897 \\
Price Level & 58.621 \\
\hline
\end{tabular}

This result shows that customers pay more attention to the price level and then the charging way. So we show the utility value results of price level and charging way as Figure 2 and Figure 3:

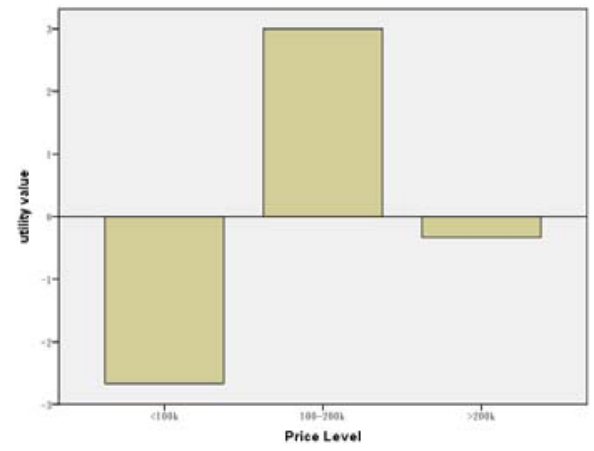

Fig. 3. Price level of customer

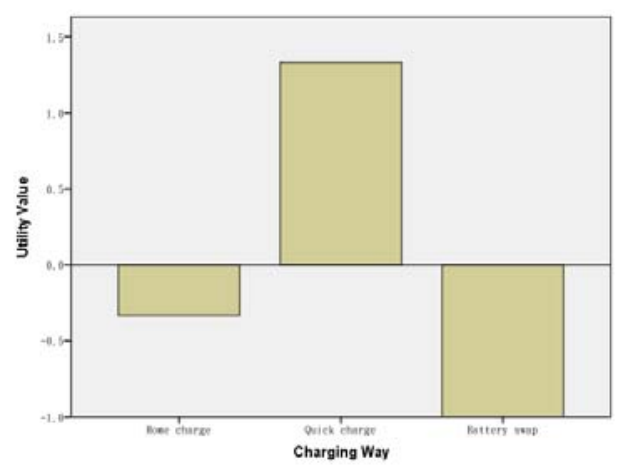

Fig. 4. Charging way of customer

(2) Producer Optimal: Based on questionnaire data we collected, an average of the requirements of most staffs in the manufacturers, producers prefer a production with the following attributes and levels in a total utility value $U=5.00$ : According to the SPSS analyze, we can get the "attribute importance degree" of customers as Table 2:

Table. 2. Attribute importance degree

\begin{tabular}{|l|c|}
\hline Charging Way & 51.613 \\
Driving Mileage & 9.677 \\
Maximum Speed & 12.903 \\
Price Level & 25.806 \\
\hline
\end{tabular}

This result shows that customers pay more attention to the charging way and then the price level. So we show the utility value results of price level and charging way as Figure 5 and Figure 6:

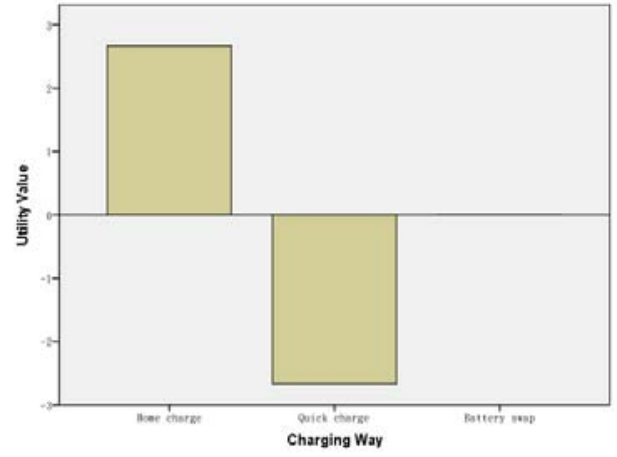

Fig. 5. Charging way of producer

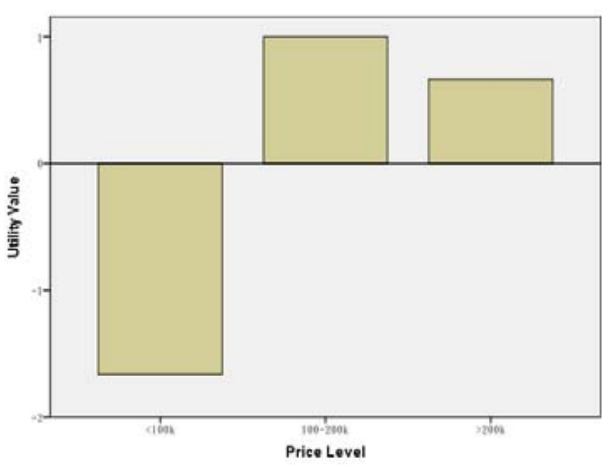

Fig. 6. Price level of producer

(3) Customer and Producer Optimal: We should notice that when customers prefer a production with a total utility value $\mathrm{V}^{*}=5.33$, the total utility of producers is $U=-2.67$. While when producers prefer a production with a total utility value $\mathrm{U}^{*}=5.00$, the total utility of customer is $\mathrm{V}=2$. Obviously, 
both options are not optimal.As the model in the 2.2, the data sets of two parts can be used to minimize the loss by the Taguchi loss function to satisfy the needs and wants of the customers and producers as optimal as possible. So, we just need to look for minimizing the loss $Z_{\min }$.

Through calculating formula 5 , we get the best choice where $\mathrm{Z}_{\min }=0.23$. And we get the target production as table 3 :

Table. 3. Optimal production

\begin{tabular}{|c|c|c|c|}
\hline Charging Way & Driving Mileage & Maximum Speed & Price Level \\
\hline Home charge & $150-250 \mathrm{~km}$ & $80-120 \mathrm{kmh}$ & $100-200 \mathrm{k}$ \\
\hline
\end{tabular}

\section{Summary and future directions}

This paper uses the conjoint analysis to construct the construction of new energy vehicles attribute and level model. Firstly, we can learn from the conjoint analysis that what attributes and levels are customers and producers paid more attention to and then to quantify it. Finding consumer potential attribute preferences will be beneficial to new energy vehicle market promotion. Secondly, the ability and the willingness of manufacturer were included in the model which makes this model more close to reality. Finally, we get a balanced production that is "better" and the loss was minimizing to 0.23.

On the whole, this article provides a quantitative method for new energy automobile attributes and levels. This model can help new energy automobile producer to know what kind of attributes and levels are more attractive for customers. What is more important, this preference is not based on attributes and their level, but is based on a complete product. We got the highest score of product specific attributes and levels which mean it can be more easily accepted by more people. It can help car manufacturers choose the more popular new energy automobile models. Compared with other methods, this article considers the ability and the willingness of manufacturer, which makes the quantification more close to reality.

\section{Acknowledgement}

This research is sponsored by National Nature Science Foundation of China (No. 71125002), and all shortcoming remains to the author.

\section{References}

[1] Luce R, Tukey J. Simultaneous conjoint measurement: A new type of fundamental measurement[J]. Journal of Mathematical Psychology, 1964, (1): 1-27

[2] Green P. Thirty Years of Conjoint Analysis: Reflections and Prospects [J]. Interfaces, 2001, (5): $56-73$

[3] Wittink DR, Cattin P. Commercial use of conjoint analysis: An update. Journal of Marketing, 1989, 53:91-96

[4] Kley F, Lerch C, Dallinger D. New business models for electric cars - A holistic approach[J]. Energy Policy, 2011, 39(6): 3392-3403.

[5] Dijk M, Orsato R J, Kemp R. The emergence of an electric mobility trajectory[J]. Energy Policy, 2013, 52: 135-145.

[6] Nan Ye. Explore the "attitude - action of new energy vehicles using gap" [J]. East China Economic Management. 2012 (11): 135-137. 